\title{
Endothelial Dysfunction and Circulating Microparticles from Patients with Obstructive Sleep Apnea
}

Pascaline Priou, ${ }^{* \dagger}$ Frédéric Gagnadoux, ${ }^{* \dagger}$ Angela Tesse, ${ }^{*}$ Maria Letizia Mastronardi, ${ }^{*}$ Abdelali Agouni, ${ }^{*}$ Nicole Meslier, ${ }^{\dagger}$ Jean-Louis Racineux, ${ }^{\dagger}$ Maria Carmen Martinez, ${ }^{*}$ Wojciech Trzepizur, ${ }^{, \dagger}$

and Ramaroson Andriantsitohaina*

From INSERM U771, Centre National de la Recherche Scientifique UMR 6214, Université d'Angers; and the Département de Pneumologie, ${ }^{\dagger}$ Centre Hospitalier Universitaire d'Angers, Angers, France

Endothelial dysfunction is involved in vascular complications of obstructive sleep apnea (OSA). In this study, circulating microparticles (MPs) from patients with OSA-induced nocturnal desaturations were characterized and their effects on endothelial function were evaluated. Two age-matched groups of patients undergoing polysomnography for OSA were compared: 35 desaturators with a $3 \%$ oxyhemoglobin desaturation index (ODI) $\geq 10$ events per hour of sleep and 27 nondesaturators with ODI $<10$ events per hour. MPs were characterized by flow cytometry and then either used to treat in vitro human endothelial cells or to study endothelial function in mice. Circulating MPs did not differ between groups, but MPs from granulocytes and activated leukocytes $\left(\mathrm{CD} 6 \mathrm{~L}^{+}\right)$ were found at higher levels in desaturators. In vitro, MPs from desaturators reduced endothelial nitric oxide (NO) production by enhancing phosphorylation of endothelial NO synthase at the site of inhibition and expression of caveolin-1. CD62 ${ }^{+}$MPs positively correlated with ODI. Endothelial NO production negatively correlated with both $\mathrm{CD}^{2} 2 \mathrm{~L}^{+}$MPs and ODI. MPs from desaturators increased expression of endothelial adhesion molecules including E-selectin, ICAM-1 and ITGA5, and cyclooxygenase 2. Moreover, injection of MPs from desaturators into mice impaired endothelium-dependent relaxation in aorta and flow-induced dilation in small mesenteric arteries. This study demonstrates an association between endothelial dysfunction and increased circulating levels of $\mathrm{CD}^{2} \mathrm{~L}^{+}$MPs. This may initiate atherogenic processes in patients with OSA and severe nighttime hypoxia. (Am J Pathol 2010, 177:974-983; DOI: 10.2353/ajpath.2010.091252)

Obstructive sleep apnea (OSA) is a highly prevalent disease characterized by recurrent episodes of partial or complete obstruction of the upper airways during sleep, leading to repeated falls in oxygen saturation. There is growing evidence in support of an independent association between OSA and cardiovascular diseases, ${ }^{1}$ particularly for sleep disordered breathing accompanied by marked nocturnal oxygen desaturations. ${ }^{2,3}$ Various pathophysiological mechanisms have been proposed to contribute to the pathogenesis of vascular morbidity, including autonomic dysfunction, hypercoagulability, inflammation, oxidative stress, and endothelial dysfunction. ${ }^{4}$ An impairment of endothelial function has been recently demonstrated in patients with OSA and nocturnal desaturations compared with matched OSA patients without desaturations. ${ }^{5}$ Very recently, it was shown that OSA directly affects the vascular endothelium by promoting inflammation and oxidative stress, and decreasing nitric oxide (NO) availability and repair capacity, as shown by reduced circulating levels of endothelial progenitor cells. ${ }^{6}$

Microparticles (MPs) are small membrane vesicles that are shed from cells in response to activation and apoptosis. The number, cellular source, and composition of MPs are altered in various disease states including diabetes, metabolic syndrome, sepsis, and pre-eclampsia. ${ }^{7-10} \mathrm{Re}-$

Supported by institutional grants from the Fonds Européen pour le Développement Régional (No. 8891, to R.A.), the Centre National de la Recherche Scientifique, INSERM, the Université d'Angers, and the Contrat d'Interface INSERM (R.A.), the Société de Pneumologie de Langue Française (F.G.), and the Association Ligérienne pour le Traitement à Domicile, I'Innovation et la Recherche.

Accepted for publication April 22, 2010.

Address reprint requests to Dr. Ramaroson Andriantsitohaina, Ph.D., INSERM U771-CNRS UMR 6214, Faculté de Médecine, Rue Haute de Reculée, 49045 Angers, France. E-mail: ramaroson.andriantsitohaina@univ-angers.fr. 
cent data suggested that MPs might play a major role in interactions with circulating cells or the components of the vessel wall. MPs have been implicated in coagulation, inflammation, and vascular function. ${ }^{11}$ With regard to OSA, Geiser et al ${ }^{12}$ did not report an increase of plateletderived MPs despite enhanced in vivo platelet activation. Recently, Ayers et $\mathrm{al}^{13}$ found that procoagulant, platelet-, and leukocyte-derived MPs were significantly increased in patients with OSA with marked nocturnal desaturations (>7.5 oxygen desaturations per hour).

To our knowledge, the role of circulating MPs in the regulation of endothelial dysfunction in OSA is unknown. Thus, the aims of this study were to characterize circulating MPs from patients with OSA according to their cellular origins and determine in vitro effects of MPs from OSA patients on endothelial cells with respect to $\mathrm{NO}$ and superoxide anion $\left(\mathrm{O}_{2}^{-}\right)$productions and the expression of adhesion and proinflammatory molecules involved in inflammation. Finally, MPs were injected into mice intravenously to test their pathophysiological relevance.

\section{Materials and Methods}

\section{Patients}

Sixty-two male patients (18 to 65 years old) were investigated by polysomnography to evaluate sleep disordered breathing between July 2007 and January 2010 and were prospectively screened for this study. Exclusion criteria included previous treatment for OSA, history of coronary artery disease, heart failure, stroke, hypertension, diabetes mellitus, dyslipidemia, and receiving any drug known to affect endothelial function. All patients underwent nocturnal polysomnography performed as previously described ${ }^{14}$ and were scored manually according to standard criteria. ${ }^{15}$ Daytime sleepiness was assessed by the Epworth sleepiness scale. ${ }^{16}$ In line with recent data demonstrating the key role of nocturnal desaturations in vascular complications of OSA, ,3,5,17 two groups of patients were compared according to the oxyhemoglobin desaturation index $\geq 3 \%$ (ODI): a desaturator group with $\mathrm{ODI} \geq 10$ events per hour of sleep and a nondesaturator group with ODI $<10$ events per hour of sleep. The study was approved by the University of Angers ethics committee, and patients gave informed consent.

\section{MP Isolation}

Blood samples from desaturators and nondesaturators were taken in the morning following polysomnography after overnight fasting and were collected in EDTA tubes (Vacutainers, Becton Dickinson, Le Pont de Claix, France) from a peripheral vein using a 21-gauge needle to minimize platelet activation and were processed for assays within 2 hours. Samples were centrifuged for 20 minutes at $270 \times g$. Plasma was harvested and centrifuged 20 minutes at $1500 \times g$ to obtain platelet-free plasma (PFP). Two hundred microliters of PFP were frozen and stored at $-80^{\circ} \mathrm{C}$ for subsequent use. As previously described, remaining PFP was subjected to three series of centrifugations at $21,000 \times g$ for 45 minutes to eliminate plasma and to pellet MPs for in vitro and in vivo studies. Supernatant was replaced by $0.9 \%$ saline salt solution. ${ }^{9,10} \mathrm{MP}$ pellets were resuspended in $150 \mu \mathrm{l}$ of $0.9 \%$ saline salt solution and stored at $4^{\circ} \mathrm{C}$ for subsequent use. Washing medium from the last supernatant was used as control.

\section{Characterization of MP Phenotype}

MP subpopulations were discriminated in PFP according the expression of membrane-specific antigens by flow cytometer. ${ }^{9,10}$ MPs derived from platelets, erythrocytes, leukocytes, endothelial cells, and granulocytes were performed using anti-CD41, anti-CD235a, anti-CD45, antiCD146, and anti-CD66b antibodies, respectively. AntiCD62P and anti-CD62L antibodies were used to identify P-selectin ${ }^{+}$and L-selectin ${ }^{+}$MPs, respectively. Irrelevant human IgG was used as an isotype-matched negative control for each sample. Annexin V (Beckman Coulter, Villepinte, France) binding was used to numerate phosphatidylserine-expressing MPs $(2 \mu \mathrm{l}$ of annexin V/5 $\mu$ l PFP). To determine concentration of MPs, $10 \mu$ l of PFP was incubated with $5 \mu$ l of a specific antibody (Beckman Coulter). After 45 minutes of incubation, samples were diluted in $300 \mu \mathrm{l}$ of $0.9 \%$ saline salt solution or annexin- $V$ labeling buffer. An equal volume of sample and Flowcount beads were then added to measure MP concentration. Samples were analyzed in a flow cytometer 500 MPL System (Beckman Coulter). Regions corresponding to MPs were identified in forward light scatter and sideangle light scatter intensity dot plot representation set at logarithmic gain, depending on their diameter $(0.1-1$ $\mu \mathrm{m})$. Sample analysis was stopped after the count of 10,000 events.

\section{Endothelial $\mathrm{NO}$ and $\mathrm{O}_{2}^{-}$Productions Assessed by Electronic Paramagnetic Resonance (EPR)}

EA hy926 endothelial cells were treated for 24 hours by MPs from desaturators or nondesaturators at concentrations equivalent to patient circulating blood MPs. ${ }^{9,10}$ Detection of NO production was performed using the technique with $\mathrm{Fe}^{2+}$ diethyldithiocarbamate (DETC; Sigma-Aldrich, St. Quentin, Fallavier, France) as spin trap as described previously. ${ }^{9,10}$ Briefly, cells were treated with $250 \mu \mathrm{l}$ of colloid $\mathrm{Fe}(\mathrm{DETC})_{2}$ and incubated at $37^{\circ} \mathrm{C}$ for 45 minutes. NO measurements were performed on a tabletop x-band spectrometer miniscope (MS200; Magnettech, Berlin, Germany). Values are expressed as amplitude of signal per protein concentration.

For $\mathrm{O}_{2}^{-}$quantification, cells were allowed to equilibrate in deferoxamine-chelated Krebs-Hepes solution containing 1-hydroxy-3-methoxycarbonyl-2,2,5,5-tetramethylpyrrolidin ( $\mathrm{CMH}$; Noxygen, Mainz, Germany) (500 $\mu \mathrm{mol} / \mathrm{L})$, deferoxamine $(25 \mu \mathrm{mol} / \mathrm{L})$, and DETC ( $5 \mu \mathrm{mol} / \mathrm{L})$ under constant temperature $\left(37^{\circ} \mathrm{C}\right)$ for 20 minutes. ${ }^{9,10}$ Cells were then scraped and frozen in plastic tubes and analyzed in a Dewar flask by EPR spectroscopy. For EPR 
Table 1. Baseline Characteristics of Patients

\begin{tabular}{lccc}
\hline Characteristics of patients & Nondesaturator group $n=27$ & Desaturator group $n=35$ & $P$ value \\
\hline Age, years & $46.8 \pm 2.4$ & $48.9 \pm 1.3$ & $\mathrm{~ns}$ \\
Body mass index, $\mathrm{kg} / \mathrm{m}^{2}$ & $25.5 \pm 0.8$ & $26.4 \pm 0.6$ & $\mathrm{~ns}$ \\
Systolic BP, $\mathrm{mm} \mathrm{Hg}$ & $137 \pm 14$ & $136 \pm 21$ & $\mathrm{~ns}$ \\
Diastolic BP, $\mathrm{mm} \mathrm{Hg}$ & $63 \pm 20$ & $64 \pm 11$ & $\mathrm{~ns}$ \\
Smokers, $n$ & 3 & 2 & $\mathrm{~ns}$ \\
Epworth sleepiness scale & $9.1 \pm 1.0$ & $9.1 \pm 1.0$ & $\mathrm{~ns}$ \\
Total cholesterol, mmol/dl & $5.3 \pm 0.3$ & $5.3 \pm 0.2$ & $\mathrm{~ns}$ \\
$\mathrm{HDL}$ cholesterol, mmol/dl & $1.5 \pm 0.1$ & $1.4 \pm 0.1$ & $\mathrm{~ns}$ \\
Triglycerides, mmol/dl & $1.3 \pm 0.1$ & $5.6 \pm 0.1$ & $\mathrm{~ns}$ \\
Plasma glucose, mmol/L & $5.6 \pm 0.2$ & $5.7 \pm 0.1$ & $\mathrm{~ns}$ \\
$\mathrm{HemoglobinA} 1 \mathrm{c}, \%$ & $5.4 \pm 0.1$ & $31.1 \pm 3.1$ & $\mathrm{~ns}$ \\
$\mathrm{AHI}(\mathrm{n} / \mathrm{h})$ & $11.4 \pm 1.7$ & $93.1 \pm 0.3$ & $<0.001$ \\
$\mathrm{Mean} \mathrm{SaO}$ (\%) & $94.3 \pm 0.3$ & $31.1 \pm 3.6$ & $<.008$ \\
ODI $(\mathrm{n} / \mathrm{h})$ & $4.5 \pm 0.6$ & $<0.001$ \\
\hline
\end{tabular}

All values expressed as mean \pm SD. BP indicates blood pressure; HDL, high-density lipoproteins; LDL, low-density lipoproteins; AHI, apneahypopnea index; $\mathrm{SaO}_{2}$, oxyhemoglobin saturation; $\mathrm{ODI}$, oxyhemoglobin desaturations index.

study, values are expressed as amplitude of signal per protein concentration.

\section{Western Blotting}

Endothelial cells were homogenized and lysed. Proteins $(40 \mu \mathrm{g}$ ) were separated using $10 \%$ sodium dodecyl sulfate-polyacrylamide gel electrophoresis. Blots were probed with anti-endothelial NO synthase (eNOS), caveolin-1 (BD Biosciences, San Jose, CA), phosphoeNOS Ser 1177, phospho-eNOS Thr 495 (Cell Signaling, Beverly, MA), intercellular adhesion molecule (ICAM)-1, ITAG5, cyclooxygenase (COX)-2 (Santa Cruz Biotechnology, Santa Cruz, CA), E-selectin (R\&D systems, Minneapolis, MN), and $\beta$-actin (Sigma-Aldrich).

\section{Quantitative Real-Time Reverse Transcription- Polymerase Chain Reaction (RT-PCR) Analysis}

After treatment with MPs, endothelial cells were frozen in liquid $\mathrm{N}_{2}$. Expression of $63 \mathrm{mRNA}$ was measured by RT-PCR using Chromo 4tm and SYBR Green detection. Quantification was calculated using to the $\Delta$ Ct method as previously described. ${ }^{18}$

\section{Ex Vivo Vascular Reactivity}

All animal studies were performed using approved institutional protocols. MPs were injected into the tail vein of male Swiss mice at circulating concentrations of MPs detected in the blood of patients ${ }^{9,10}$ or washing medium. After 24 hours, aortic rings and small mesenteric arteries (SMAs) were obtained from animals and mounted on a wire myograph or arteriograph for measurement of vascular reactivity. ${ }^{19}$ Endothelial-dependent vasodilatation was assessed by cumulative applications of acetylcholine ( $1 \mathrm{nmol} / \mathrm{L}$ to $10 \mu \mathrm{mol} / \mathrm{L}$, Sigma-Aldrich) on aortic rings with functional endothelium after a precontraction using U46619 $0.1 \mu \mathrm{mol} / \mathrm{L}$ (Sigma-Aldrich). In another set of experiments, SMAs were precontracted with U46619 fol- lowed by cumulative applications of sodium nitroprusside (0.1 nmol/L to $10 \mu \mathrm{mol} / \mathrm{L}$, Sigma-Aldrich).

SMAs (100-130 $\mu \mathrm{m}$ of diameter) were cannulated at both ends in a video-monitored perfusion system (Living Systems Instrumentation, Burlington, VT). Arteries were bathed in physiological salt solution $\left(\mathrm{pH} 7.4, \mathrm{PO}_{2} 160\right.$ $\mathrm{mm} \mathrm{Hg}, \mathrm{PCO}_{2} 37 \mathrm{~mm} \mathrm{Hg}$ ). Pressure was controlled by a servoperfusion system, and flow was generated by a peristaltic pump. Diameter changes were measured when intraluminal pressure increased from 10 to 125 $\mathrm{mm} \mathrm{Hg}$. The presence of endothelium was studied by applying acetylcholine $(10 \mu \mathrm{mol} / \mathrm{L})$, after precontraction of the arteries with $\mathrm{U} 46619(1 \mu \mathrm{mol} / \mathrm{L})$. Pressure was then set at $75 \mathrm{~mm} \mathrm{Hg}$, and dilation in response to flow was performed. The different components of the dilation were determined as follows: the NO-dependent dilation was calculated as the difference between the dilation in the absence of inhibitors and the dilation in the presence of NO synthase inhibitor $N^{G}$-nitro-L-arginine (L-NA, 100 $\mu \mathrm{mol} / \mathrm{L}$; Sigma-Aldrich). The dilation dependent to COX products was obtained as the difference between the dilation in the presence of L-NA alone and the dilation in the presence of L-NA plus indomethacin. The EDHF component was assessed in the presence of L-NA plus indomethacin. The EDHF component was completely abolished by $15 \mathrm{mmol} / \mathrm{L} \mathrm{KCl}$ depolarizing physiological salt solution.

\section{Data Analysis}

Data are presented as mean \pm SEM, and $n$ represents the number of patients. Sensitivities to acetylcholine were expressed as $\mathrm{pD}_{2}$ values, where $\mathrm{pD}_{2}=-\log \mathrm{EC}_{50}, \mathrm{EC}_{50}$ being the molar concentration of the agonist that produces $50 \%$ of the maximal effect. Statistical analyses performed were as follows: a one-way analysis of variance and Mann-Whitney U-test for data analysis between groups, or two-way analysis of variance for repeated measurements followed by a Bonferroni post hoc test to analyze relaxation curves between groups. The Spear- 
A

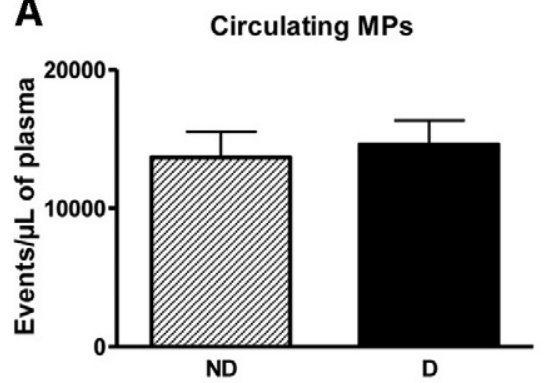

D

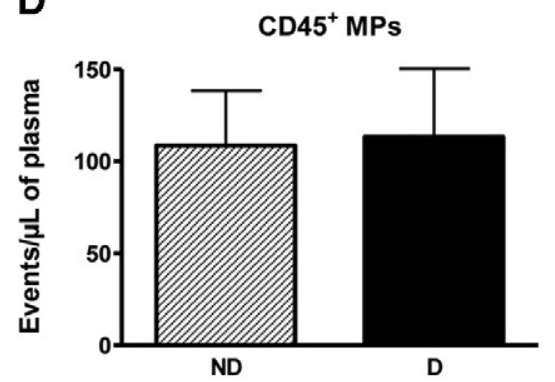

G

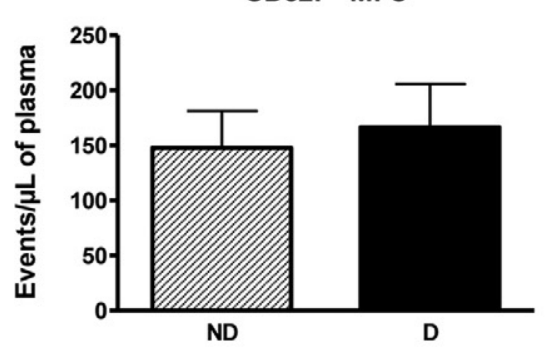

B

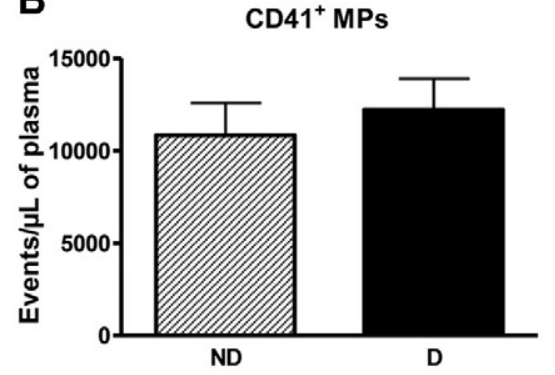

E

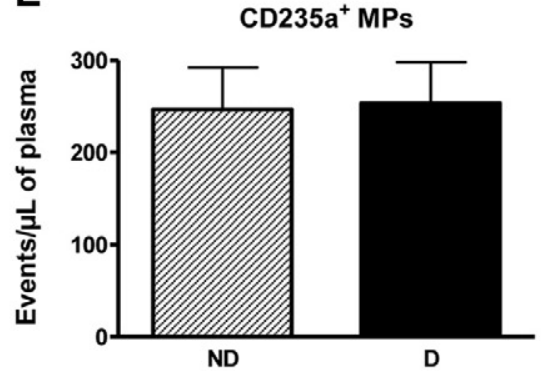

H

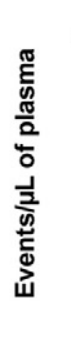

C

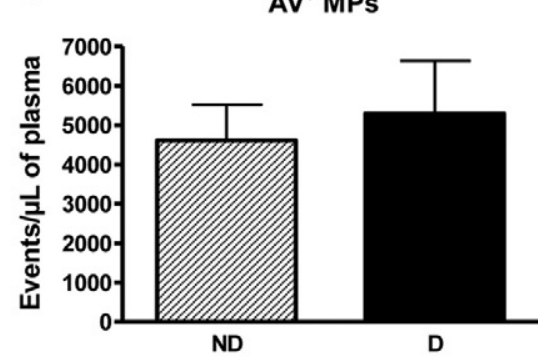

$\mathbf{F}$

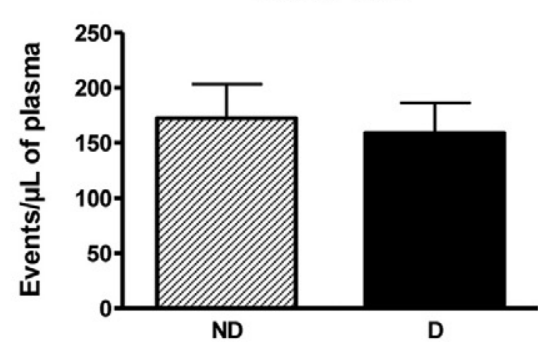

$\mathrm{CD}_{6} \mathrm{~b}^{+} \mathrm{MPs}$

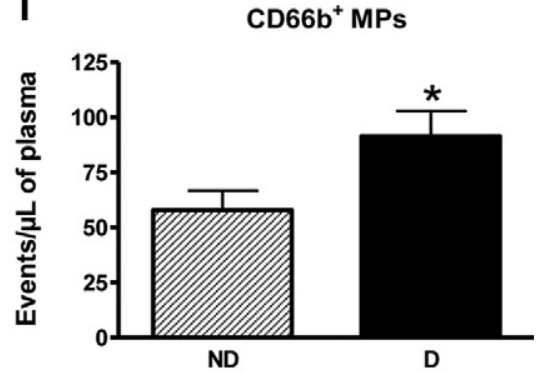

Figure 1. Circulating microparticle (MP) levels in desaturators (D) compared with nondesaturators (ND) patients. Total circulating MPs (A), platelet-derived $\left(\mathrm{CD} 41^{+}\right)$MPs $(\mathbf{B})$, procoagulant (annexin $\left.\mathrm{V}^{+}\right)$MPs $(\mathbf{C})$, leukocyte-derived $\left(\mathrm{CD} 45^{+}\right)$MPs (D), erythrocyte-derived $\left(\mathrm{CD} 235 \mathrm{a}^{+}\right) \mathrm{MPs}(\mathbf{E})$, endothelium-derived

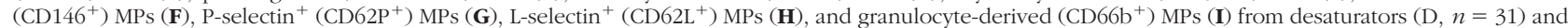
from nondesaturators (ND, $n=23$ ) patients. ${ }^{*} P<0.05 ;{ }^{* *} P<0.001$.

man's rank correlation coefficient was used to correlate MP levels with clinical, biological, and polysomnographic data. $P<0.05$ was considered to be statistically significant.

\section{Results}

\section{Baseline Clinical and Biological Characteristics}

Sixty-two male patients were included in this study. Patients were split into groups of desaturators $(n=35)$ or nondesaturators $(n=27)$ according to ODI, which was determined by overnight polysomnography. As shown in Table 1, the two groups did not differ for age, body mass index, blood pressure, Epworth sleepiness scale, lipid metabolism, glucose metabolism, and in the smoking rate. Using an apnea-hypoapnea index ( $\mathrm{AHI})$ cut-off of 15 events per hour of sleep, ${ }^{20}$ OSA was diagnosed in all desaturators and 7/27 nondesaturators. In the nondesaturator group, OSA was characterized by a large predominance of awaking but non desaturating hypopneas.

\section{Circulating MPs and Their Cellular Origin}

Comparison between nondesaturators and desaturators showed no significant difference for the total number of circulating MPs (Figure 1A). Phenotypical characterization of cellular origin of MPs showed a significant increase of MPs from granulocytes $\left(\mathrm{CD} 6 \mathrm{~b}^{+}\right)$and MPs expressing $\mathrm{L}$-selectin $\left(\mathrm{CD}_{2} \mathrm{~L}^{+}\right.$) in desaturators compared with nondesaturators, even though absolute numbers of leukocytes and granulocytes were not significantly different between nondesaturator and desaturator patients (5552 \pm 322 versus $5954 \pm 315$ and $3034 \pm 276$ versus $3218 \pm 322$, respectively). MPs of other cellular origins were not significantly different between the two groups including procoagulant MPs, those from platelets, leukocytes, erythrocytes, endothelial cells, and MPs expressing P-selectin. Correlation analysis for the overall population showed that ODI but not $\mathrm{AHI}$ correlated significantly with $\mathrm{CD}_{2} \mathrm{~L}^{+} \mathrm{MPs}(r=0.28, P=0.029)$. Among clinical and biological data, CD62L ${ }^{+} \mathrm{MPs}$ correlated only with hemoglobinA1c $(r=0.31, P=0.023)$. HemoglobinA1c 
A NO production

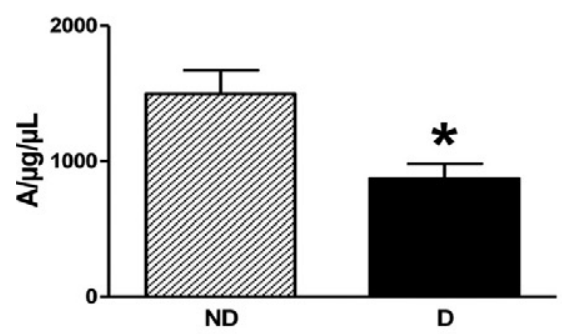

C

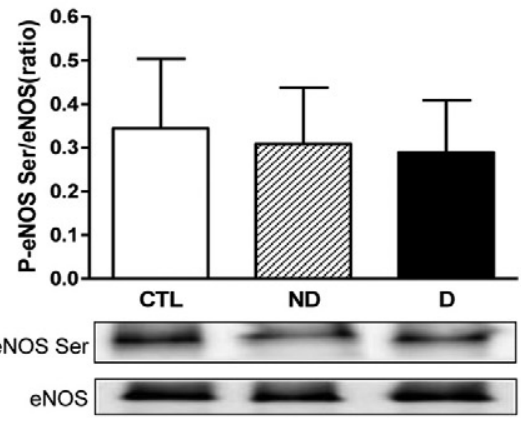

B

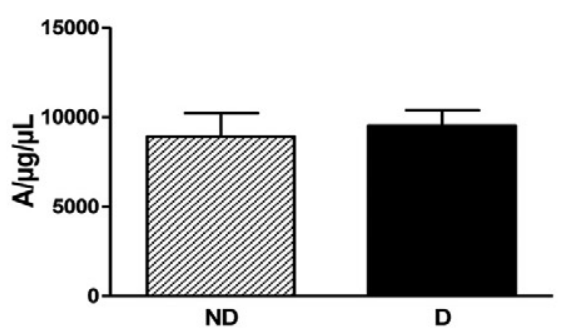

D

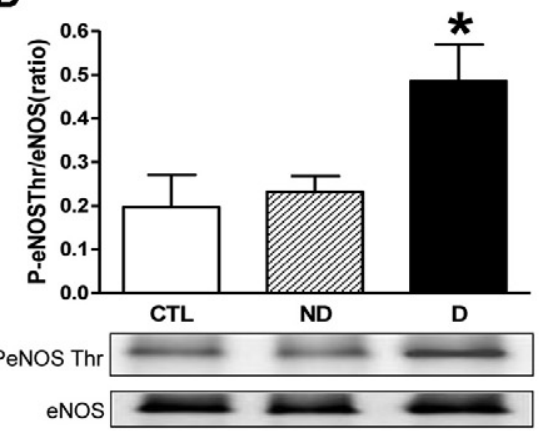

Figure 2. Nitric oxide (NO) and superoxide anion $\left(\mathrm{O}_{2}^{-}\right)$productions and Western blots studying eNOS pathway in endothelial cells incubated with washing medium (CTL), microparticles (MPs) from desaturator (D) or nondesaturator (ND) patients. Values are expressed in units of amplitude $/ \mu \mathrm{g} / \mu \mathrm{l}$ of proteins as mean \pm SEM [for NO production $(\mathbf{A}), n=11-13$; for $\mathrm{O}_{2}^{-}$production $(\mathbf{B}), n=6$ ]. Histograms show the ratio of phosphorylation of eNOS Ser 1177 (C) and eNOS Thr 495 (D) versus total eNOS and caveolin-1 expression (E) $(n=3-4)$. Immunoblots were quantified by densitometric analysis and normalized with either the full form of corresponding protein or with $\beta$ actin (for caveolin-1). ${ }^{*} P<0.05$.

E

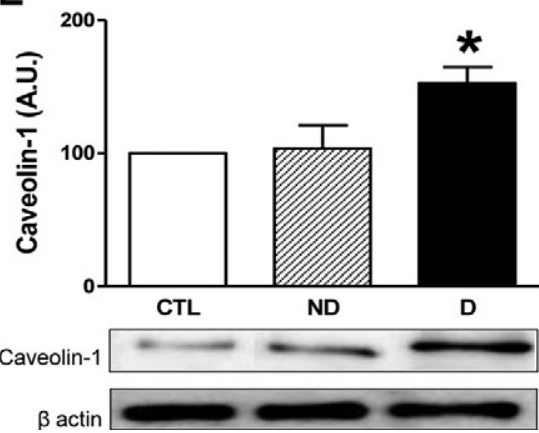

was also significantly correlated with ODI $(r=0.31, P=$ $0.02)$. There was no significant correlation between $\mathrm{ODI}$ and $\mathrm{CD}_{6} \mathrm{~b}^{+} \mathrm{MPs}(r=0.22, P=0.08)$.

\section{$\mathrm{NO}$ and $\mathrm{O}_{2}^{-}$Production by Endothelial Cells Treated by MPs}

MPs from desaturators significantly reduced NO release in endothelial cells by approximately $40 \%$ compared with MPs from nondesaturators (Figure 2A). Heat-inactivated MPs did not have the capacity to reduce NO production (not shown). These data are in favor of the hypothesis that the effects of MPs are mediated by protein-related process. EPR measurement of $\mathrm{O}_{2}^{-}$production showed no difference between both groups (Figure 2B).

Expression of eNOS was not modified by the different treatments (Figure 2, C and D). MPs from desaturators did not alter eNOS phosphorylation on its activator (Ser 1177 ) site but they significantly increased its phosphorylation at the inhibitor (Thr 495) site (Figure 2, C and D) when compared either to nontreated or those treated with MPs from nondesaturators. It should be noted that MPs either from nondesaturator or desaturator patients did not modify inducible NOS expression in endothelial cells under the same experimental conditions (data not shown).

As shown in Figure 2E, only MPs from desaturators were able to increase expression of caveolin-1.

To assess physiological pertinence, we studied correlations between clinical parameters, MP origins, and their capacity in reducing endothelial NO release from cultured human endothelial cells. Interestingly, we found a negative correlation between $\mathrm{ODI}$ and NO production (Figure 3A). Furthermore, $\mathrm{CD}_{2} \mathrm{~L}^{+} \mathrm{MP}$ count negatively correlated with endothelial NO production (Figure 3B). No significant correlation was found between $\mathrm{NO}$ production and any clinical or biological data including CD66 $\mathrm{b}^{+} \mathrm{MPs}(r=0.083, P=0.71)$.
MPs from Desaturator Patients Regulate Adhesion and Proinflammatory Molecule Expressions

Adhesion molecule expressions were analyzed by realtime quantitative RT-PCR using a panel of different hu-

A

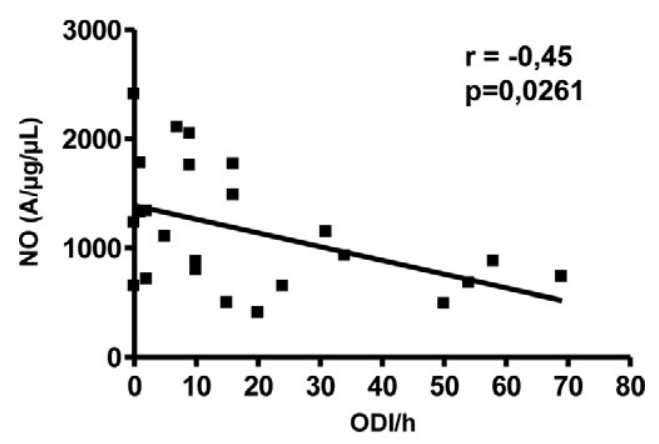

B

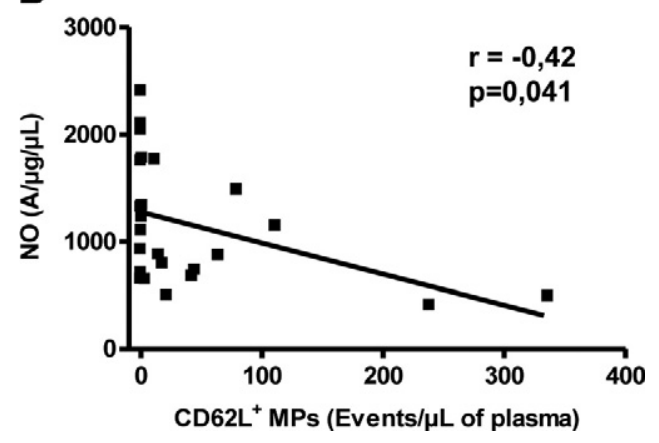

Figure 3. Correlations between nitric oxide (NO) production, oxygen desaturation index (ODI), and number of $\mathrm{CD}_{2} 2 \mathrm{~L}^{+}$microparticles (MPs). Correlations between NO release induced by MPs in EA hy926 cells with ODI/h (A) and $\mathrm{CD}_{6} \mathrm{~L}^{+}$MP levels $(\mathbf{B})$. 
Table 2. Effects of Microparticles (MPs) on Different mRNA Expression

\begin{tabular}{|c|c|c|c|}
\hline mRNA & $\begin{array}{c}\text { Ratio MPs from } \\
\text { nondesaturators/ } \\
\text { CTL }\end{array}$ & $\begin{array}{c}\text { Ratio MPs from } \\
\text { desaturators/ } \\
\text { CTL }\end{array}$ & $\begin{array}{c}P \\
\text { value }\end{array}$ \\
\hline Alk-1 & 1.43 & 1.46 & NS \\
\hline ANG-1 & 1.33 & 1.45 & NS \\
\hline Angiogenin & 1.02 & 1.16 & NS \\
\hline AP1 & 1.28 & 1.13 & NS \\
\hline CD148 & 1.2 & 1.51 & NS \\
\hline $\mathrm{cox} 2$ & 0.8 & 2.06 & $<0.05$ \\
\hline Edg-1 & 0.91 & 1.54 & NS \\
\hline E-selectin & 1.11 & 1.69 & $<0.05$ \\
\hline FGF1 & 0.83 & 0.78 & NS \\
\hline FGF2 & 1.03 & 1.1 & NS \\
\hline FGF5 & 0.95 & 0.86 & NS \\
\hline FGF7 & 1.16 & 1.4 & NS \\
\hline FGFR1 & 1.46 & 1.57 & NS \\
\hline FLT1 & 1.34 & 1.5 & NS \\
\hline $\mathrm{HIF} 1 \alpha$ & 1.17 & 1.09 & NS \\
\hline ICAM-1 & 1.13 & 3.25 & $<0.05$ \\
\hline IL6 & 1.23 & 1.49 & NS \\
\hline ITGA5 & 1.36 & 2.2 & $<0.05$ \\
\hline ITGB3 & 0.93 & 1.35 & NS \\
\hline MT-1-MMP1 & 0.86 & 1.39 & NS \\
\hline PDGFA & 1.09 & 1.53 & NS \\
\hline PDGFB & 1.33 & 0.91 & NS \\
\hline PECAM1 & 1.79 & 2.39 & NS \\
\hline Serpin1 & 1.19 & 0.71 & NS \\
\hline TGFb1 & 0.92 & 1.34 & NS \\
\hline TGFb2 & 1.11 & 4.73 & NS \\
\hline Tie- 1 & 0.92 & 1.14 & NS \\
\hline TSP1 & 1.71 & 1.41 & NS \\
\hline VE-cadherin & 1.41 & 1.32 & NS \\
\hline VEGFA & 0.86 & 1.32 & NS \\
\hline VEGFB & 1.24 & 0.92 & NS \\
\hline VEGFC & 1.41 & 2.16 & NS \\
\hline
\end{tabular}

NS, not significant.

man adhesion molecule and angiogenic factor mRNA. Among the 63 transcripts studied, only 32 were expressed by human endothelial cells (Table 2), and those for E-selectin, ITGA5, and ICAM-1 were significantly increased by MPs from desaturators (Figure 4, A-C). Moreover, COX-2 was also overexpressed in MPs from desaturator-treated endothelial cells (Figure 4D). Western blot analysis of ICAM-1, E-selectin, ITGA5, and COX-2 showed that expressions of these proteins were increased when cells were incubated in the presence of MPs from desaturator patients (Figure 4, E-H).

\section{Endothelial Function}

The endothelium-dependent relaxation to acetylcholine was significantly impaired in aorta taken from mice injected with MPs from desaturators compared with those from mice injected with either vehicle or MPs from nondesaturators (Emax $35 \pm 5.3 \%, 61 \pm 3 \%$, and $60 \pm 4 \%$, respectively) (Figure 5A). The decrease in maximal response was associated with a leftward shift of the concentration-response curves to acetylcholine and therefore a decrease of the sensitivity to the agonist. The $\mathrm{pD}_{2}$ values were lower in MPs from desaturator-treated mice $(6.0 \pm 0.05)$ than in those treated with saline solution
$(6.6 \pm 0.12)$ or MPs from nondesaturators $(6.3 \pm 0.08)$ $(P<0.001$ for both).

To evaluate whether MPs affect smooth muscle function, concentration-response curves to sodium nitroprusside were performed in SMAs. The relaxation to sodium nitroprusside was not significantly different in SMAs from the three groups of mice (Figure 5B).

In SMAs, MPs from desaturators $(P<0.01)$ but not those from nondesaturators impaired flow-induced dilation when compared with controls (Figure 5C). The reduced flow-induced dilation by MPs from desaturators resulted in the decrease of both NO (Figure 5D) and prostacyclin components (Figure $5 \mathrm{E}$ ) but not the EDHF component (Figure 5F) of the response. Although SMAs from mice treated with MPs from nondesaturators did not affect flow-induced dilation, these vessels showed a reduced prostacyclin component (Figure 5E) that was compensated by an increased NO component of the response (Figure 5D).

\section{Discussion}

The present study demonstrated increased levels of MPs from granulocytes $\left(\mathrm{CD} 6 \mathrm{~b}^{+}\right)$and from activated leukocytes $\left(\mathrm{CD}_{2} \mathrm{~L}^{+}\right)$in patients with OSA, and frequent nocturnal hypoxemia although the circulating levels of MPs did not differ from the control group. MPs from desaturators were also shown to decrease NO production but not $\mathrm{O}_{2}^{-}$in endothelial cells in vitro. These effects were associated with an increase of phosphorylation of eNOS at the inhibitor site. Interestingly, CD62 ${ }^{+}$MPs positively correlated with ODI. Both $\mathrm{CD}_{2} \mathrm{~L}^{+} \mathrm{MPs}$ and ODI negatively correlated with endothelial NO production. Moreover, MPs from desaturators increased the expression of some of endothelial adhesion molecules and COX-2. Evidence of the pathophysiological relevance of MPs from desaturators was provided ex vivo by their capacity to impair endothelium-dependent relaxation in response to acetylcholine in the aorta and the endothelial response to flow in SMAs.

In this study, we speculated that the adverse vascular effects of OSA are mediated through nocturnal hypoxaemia and decided to compare two groups of patients according to the ODI rather than the AHI. Indeed, there is strong evidence that nocturnal desaturations play a key role in the pathophysiology of cardiovascular complications in OSA. Hypoxia-reoxygenation impairs endotheliumdependent relaxation in isolated rat aorta. ${ }^{21}$ In a study of 51 patients with OSA diagnosed by $\mathrm{AHI}>15$, Cross et $\mathrm{al}^{5}$ demonstrated impairment in vascular function in patients with frequent nocturnal desaturations compared with nondesaturator OSA patients. A recent prospective cohort study in a community sample of 6441 adults demonstrated that measures of sleep-related intermittent hypoxemia, but not sleep fragmentation, were independently associated with all-cause mortality. ${ }^{3}$ The severity of oxygen nocturnal desaturation was also found to be the best predictor of carotid wall thickening and plaque occurrence in patients with OSA. ${ }^{20}$ Conversely, prospective cohort studies showed that nondesaturating hypop- 
A

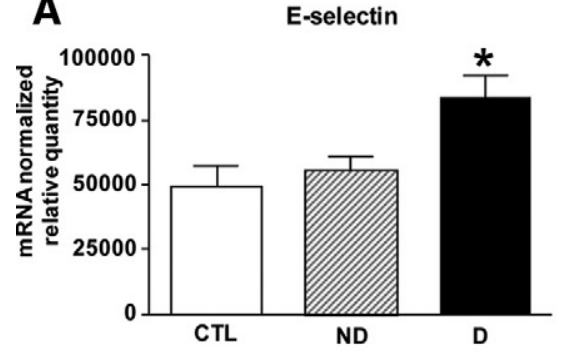

D

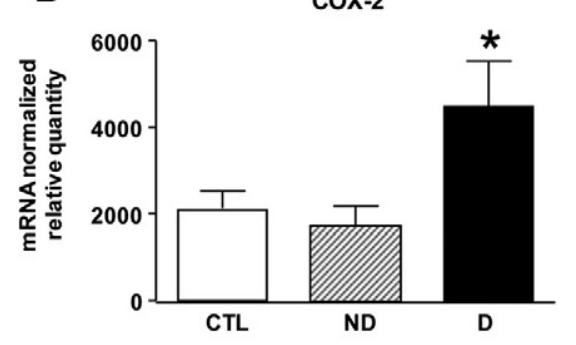

G

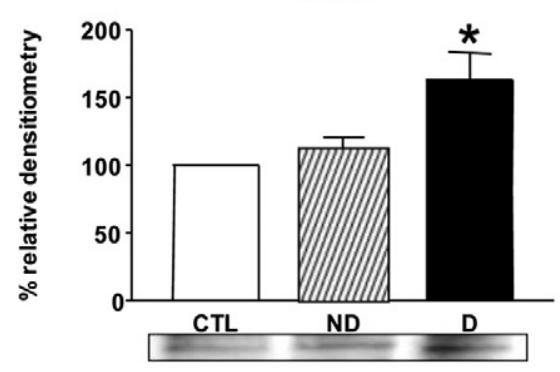

B

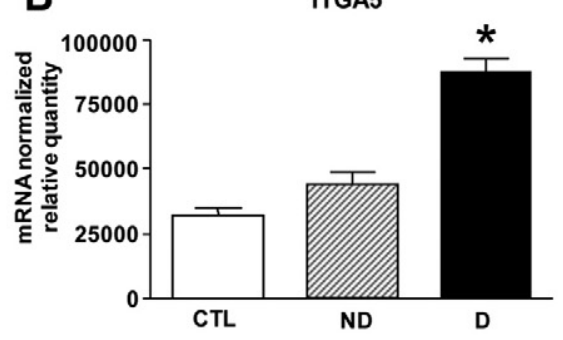

E

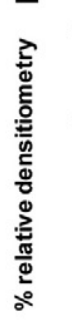

E-selectin

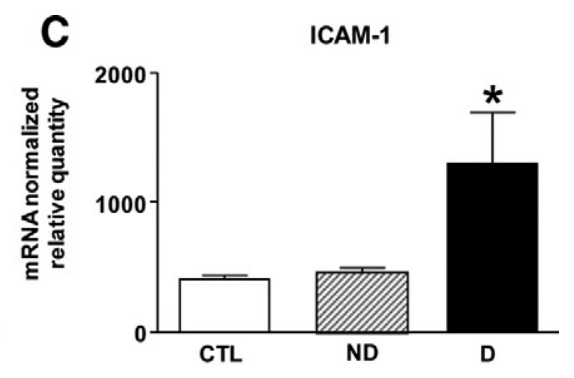

C

$\mathbf{F}$

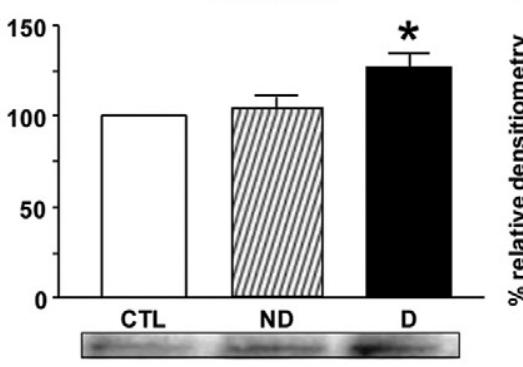

H

cox-2

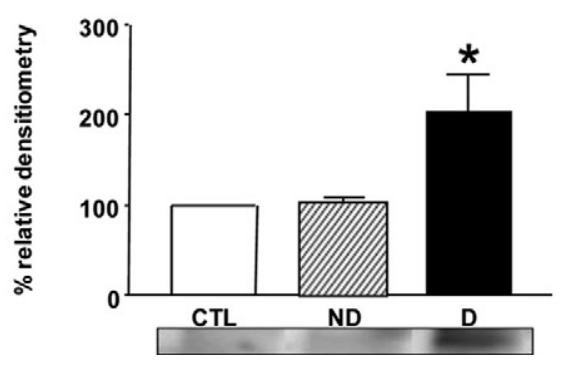

ITGA5

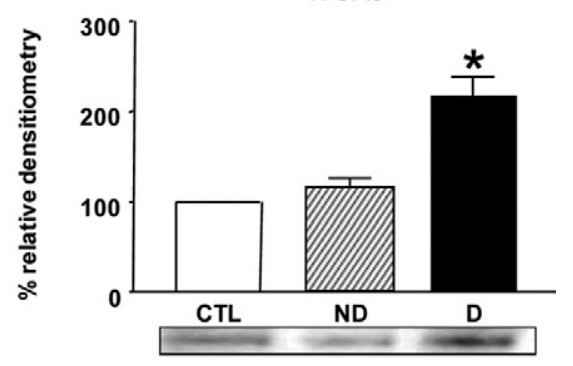

neas did not predict cardiovascular morbidity and mortality in OSA. ${ }^{2}$ To avoid confounding factors, only patients free of any other cardiovascular risk factors were included. Vascular endothelial dysfunction and inflammation in OSA without clinical evidence of cardiovascular disease has been documented very recently. ${ }^{6}$ These authors reported that endothelial repair capacity is decreased as shown by reduced circulating levels of endothelial progenitor cells in these patients.

Another key player that may contribute to this endothelial dysfunction and inflammation might be circulating MPs. Elevated circulating levels of MPs have been reported under pathological states linked to inflammation and endothelial dysfunction including pulmonary hypertension, ${ }^{22}$ ischemic heart diseases, ${ }^{23}$ pre-eclampsia, ${ }^{8}$ and lately metabolic syndrome. ${ }^{9}$ In patients with metabolic syndrome, we recently reported a link between increased circulating levels of MPs including those with procoagulant and proinflammatory properties and their involvement in promoting endothelial dysfunction ex vivo. ${ }^{9}$ With regard to OSA, Geiser et al ${ }^{12}$ did not find an increase of platelet-derived MPs despite enhanced in vivo platelet activation. In line with this report, OSA patients did not display increased platelet MPs in the present study. In contrast, Ayers et al $^{13}$ showed a significant increase of procoagulant, platelet-, and leukocyte-derived MPs, without any difference on endothelial-derived
MPs. It should be noted that although most of the baseline characteristics of the populations between Ayers et al and the present study are identical, those from Ayers et al displayed higher body mass index. Obesity has been associated with an increased level of MPs including those from endothelium and platelets, which is correlated with endothelial dysfunction in obese women. ${ }^{24,25}$ It is noteworthy that OSA patients included in the present study are free of any other cardiovascular risk factors, which might explain that desaturators did not have increased circulating levels of MPs compared with nondesaturators. Interestingly, desaturator patients displayed increased circulating levels of both granulocyte $\left(\mathrm{CD} 6 \mathrm{~b}^{+}\right)$- and activated leukocyte $\left(\mathrm{CD}_{2} \mathrm{~L}^{+}\right.$)-derived MPs. Furthermore, CD62L ${ }^{+} \mathrm{MPs}$ correlated significantly with ODI in the overall population. Among clinical and biological data, $\mathrm{CD}_{2} \mathrm{~L}^{+} \mathrm{MPs}$ correlated only with hemoglobinA1c $(r=0.31, P=0.023)$, but hemoglobinA1c was also found to be significantly correlated with ODI in the present study $(r=0.31, P=0.02)$ as well as in a recently published study demonstrating the impact of untreated OSA on glucose control in type 2 diabetes. ${ }^{26}$ In line with our data, in OSA, polymorphonuclear leukocytes (PMNs) are implicated in atherogenesis by producing oxidizing radicals ${ }^{27}$ and proteolytic enzymes during PMN-endothelium interactions. PMNs are probably one of the sources of MPs including CD66b ${ }^{+}$and $\mathrm{CD}_{2} \mathrm{~L}^{+}$-MPs. In the present study, the increase of 

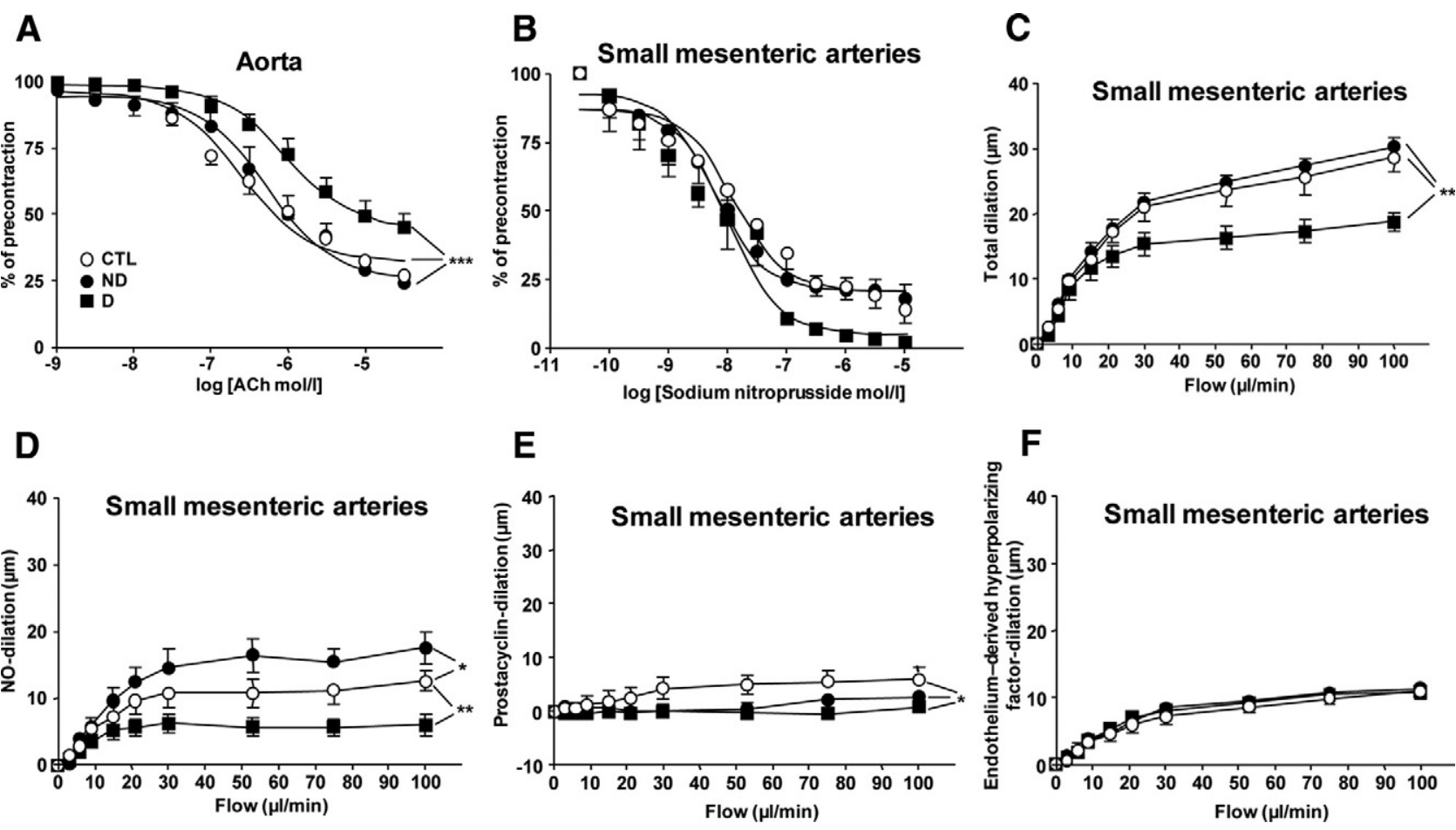

Figure 5. Alteration of endothelial function in aortic rings and small mesenteric resistance arteries (SMAs) taken from mice treated i.v. either by washing medium [controls (CTL)], microparticles (MPs) from nondesaturators (ND), and MPs from desaturators (D) patients. Acetylcholine (Ach, A)- and sodium nitroprusside (SNP, B)-induced relaxation are expressed as a percentage of U46619-induced precontraction. C: Flow-induced dilation obtained in SMAs from mice. Dilation expressed in $\mu \mathrm{m}$ in response to flow expressed in $\mu \mathrm{l} / \mathrm{min}$ : dilation dependent to nitric oxide (D), to cyclooxygenase products (E), and to endothelium-derived hyperpolarizing factor $(\mathbf{F})$. Results are given as mean $\pm \operatorname{SEM}(n=5-6)$. ${ }^{*} P<0.05 ;{ }^{* * *} P<0.01 ;{ }^{* * * * *} P<0.001$.

MPs from granulocytes (CD66 $b^{+}$MPs) did not correlate with either ODI or reduced endothelial NO production, suggesting that this type of MPs may not play a significant role in endothelial dysfunction. Of particular interest is that circulating $\mathrm{CD} 62 \mathrm{~L}^{+} \mathrm{MPs}$ (ie, MPs from activated leukocytes) were elevated in desaturators and their levels correlated with both ODI and the impairment of endothelial cells in producing NO. In conjunction with these data, Dyugovskaya et $\mathrm{al}^{28}$ have characterized the phenotype, cytokine profile, adhesion properties, and cytotoxicity of $\gamma \delta \mathrm{T}$ cells, which are known to contribute to endothelial cell damage in OSA. These authors showed that CD62L expression is greater in $\gamma \delta \mathrm{T}$ cells from OSA patients, and this is associated with increased intracellular content of proinflammatory cytokines and increased adhesion properties of these cells, suggesting their implication in atherogenic effect in OSA. We provide evidence that $\mathrm{CD}_{2} \mathrm{~L}^{+} \mathrm{MP}$ levels are correlated with the occurrence of sleep apnea and decreased endothelial-NO production. These data corroborate previous studies showing a decreased plasma concentration of $\mathrm{NO}$ metabolites in OSA, which is correlated with OSA severity. ${ }^{29}$ The mechanism by which MPs from desaturators reduced NO production from endothelial cells might be explained by a negative regulation of eNOS via both an increase of its phosphorylation on the inhibitory site and up-regulation of caveolin-1. In conjunction with the present data, we recently reported that MPs from metabolic syndrome patients reduce endothelial-NO release by a negative regulation of eNOS activity in the EA hy926 cell line. ${ }^{16}$ In the present study, we have used the same EA hy926 cell line to avoid differences due to donor of human umbilical vein endothelial cells.

Increased oxidative stress is described as one of the possible mechanisms explaining endothelial dysfunction in OSA. Indeed, several authors have shown increased production of reactive oxygen species, oxidized macromolecules (lipids, proteins, DNA) in OSA, ${ }^{30}$ and a decreased antioxidant capacity. ${ }^{31,32}$ Furthermore, endothelial oxidative stress is significantly increased in patients with OSA as evidenced by greater endothelial nitrotyrosine phosphorylation. ${ }^{6}$ In the present study, MPs from desaturators did not affect $\mathrm{O}_{2}^{-}$production by cultured endothelial cells. These results indicate that reduced endothelial-NO release is not due to increased $\mathrm{O}_{2}^{-}$production. Thus, we report the absence of a link between reactive oxygen species and endothelial dysfunction by MPs from OSA patients although increased oxidative stress has been reported in these patients.

Another mechanism that may participate in cardiovascular morbidity of OSA is vascular inflammation. As discussed above, CD62 ${ }^{+}$MPs are derived from activated leukocytes and play a key role in endothelial dysfunction. Besides, endothelial adhesion molecule mRNA and protein expressions (E-selectin, ITGA5 and ICAM-1) were enhanced after treatment with MPs from desaturators. In line with these results, circulating levels of ICAM-1, vascular cell adhesion molecule 1, and CD62L have been shown to be increased in patients with OSA. ${ }^{33-35}$ Moreover, up-regulation of COX-2 in endothelial cells treated with MPs from desaturators provided evidence for vascular inflammation in accordance with a recent manu- 
script by Jelic et $\mathrm{al}^{6}$ in which they found increased COX-2 expression in venous endothelial cells harvested from patients with untreated OSA. Altogether these data suggest vascular endothelial activation and inflammation in patients with OSA related oxygen desaturations.

Finally, in vivo treatment of mice with MPs from desaturators, but not those from nondesaturators, reduced both the ability of acetylcholine to promote endothelium-dependent relaxation in aorta and also flow-induced vasodilatation especially the $\mathrm{NO}$ and prostacyclin components of the response in SMAs. On treatment with MPs from desaturators, the reduced NO component of flowmediated dilatation was not due to decreased sensitivity of $\mathrm{NO}$ on smooth muscle cells. Although response to sodium nitroprusside was not statistically different, increased responsiveness to the NO donor on smooth muscle was shown in Figure 5B, which might take place at the level of protein kinase $\mathrm{G}$ or phosphodiesterases. Indeed, decreased endothelial NO might alleviate the desensitization effect of $\mathrm{NO}$ itself on its targets including guanylyl cyclase. One can advance the hypothesis that increased exogenous response on smooth muscle is to partially compensate the loss of functional endothelium and eNOS. Thus, these data are in accordance with the capacity of MPs from desaturators to reduce NO release in endothelial cells. Together, these results strongly suggest that circulating MPs from OSA patients with nocturnal desaturations are able to induce ex vivo endothelial dysfunction and demonstrate, for the first time, their pathophysiological relevance in OSA.

The absence of a normal control group constitutes a potential limitation to the study. It would not have been feasible to find weight-matched healthy volunteers who did not have some degree of irregular breathing during sleep. Based on previous investigations demonstrating the key role of nocturnal desaturations in vascular complications of OSA, ${ }^{2,3,5,20,21}$ we took the pragmatic approach of using a nondesaturating patient group as a control. Although we demonstrate the influence of intermittent nocturnal hypoxia on MPs release and function, the potential role of repeated airway obstruction cannot be excluded. Indeed, a recent study in a rat model of sleep apnea demonstrated that recurrent obstructive apneas induce a leukocyte-endothelial cell interaction and trigger early systemic inflammation. ${ }^{36}$ It can be hypothesized that MPs could be also implicated in the inflammatory response triggered by intermittent upper airway collapse in OSA.

In summary, we demonstrated that although OSA patients with nocturnal desaturations did not have increased levels of total circulating MPs, those expressing CD66b and CD62L were elevated. Most importantly, MPs from patients with OSA and marked nocturnal hypoxemia induced ex vivo endothelial dysfunction, reduced endothelial-NO release independently of oxidative stress, and increased endothelial adhesion molecule expressions. $\mathrm{CD} 2 \mathrm{~L}^{+} \mathrm{MP}$ levels correlate with decreased NO release by endothelial cells. One can advance the hypothesis that $\mathrm{CD}_{22} \mathrm{~L}^{+} \mathrm{MPs}$ play a significant role in endothelial dysfunction in patients with OSA.

\section{Acknowledgments}

We thank Laurence Preisser and Julien Daligault (Service Commun de Cytométrie et d'Analyses Nucléotidiques (IFR 132), University of Angers) for technical assistance in RT-PCR experiments. We also thank Carl Owen (University of Aberdeen) for critical reading of the manuscript.

\section{References}

1. Somers VK, White DP, Amin R, Abraham WT, Costa F, Culebras A, Daniels S, Floras JS, Hunt CE, Olson LJ, Pickering TG, Russell R, Woo M, Young T: Sleep apnea and cardiovascular disease: an American Heart Association/American College Of Cardiology Foundation Scientific Statement from the American Heart Association Council for High Blood Pressure Research Professional Education Committee. Council on Clinical Cardiology, Stroke Council, and Council on Cardiovascular Nursing in collaboration with the National Heart, Lung, and Blood Institute National Center on Sleep Disorders Research (National Institutes of Health). Circulation 2008, 118:1080-1111

2. Punjabi NM, Newman AB, Young TB, Resnick HE, Sanders MH: Sleep-disordered breathing and cardiovascular disease: an outcome-based definition of hypopneas. Am J Respir Crit Care Med 2008, 177:1150-1155

3. Punjabi NM, Caffo BS, Goodwin JL, Gottlieb DJ, Newman AB, O'Connor GT, Rapoport DM, Redline S, Resnick HE, Robbins JA, Shahar E, Unruh ML, Samet JM: Sleep-disordered breathing and mortality: a prospective cohort study. PLoS Med 2009, 6:e1000132

4. Kato M, Roberts-Thomson P, Phillips BG, Haynes WG, Winnicki M, Accurso V, Somers VK: Impairment of endothelium-dependent vasodilation of resistance vessels in patients with obstructive sleep apnea. Circulation 2000, 102:2607-2610

5. Cross MD, Mills NL, Al-Abri M, Riha R, Vennelle M, Mackay TW, Newby DE, Douglas NJ: Continuous positive airway pressure improves vascular function in obstructive sleep apnoea/hypopnoea syndrome: a randomised controlled trial. Thorax 2008, 63:578-583

6. Jelic S, Padeletti M, Kawut SM, Higgins C, Canfield SM, Onat D, Colombo PC, Basner RC, Factor P, LeJemtel TH: Inflammation, oxidative stress, and repair capacity of the vascular endothelium in obstructive sleep apnea. Circulation 2008, 117:2270-2278

7. Nomura S, Miyazaki Y, Miyake T, Suzuki M, Kawakatsu T, Kido H Yamaguchi K, Fukuroi T, Kagawa H, Yanabu M: Detection of plateletderived microparticles in patients with diabetes. Am J Hematol 1993, $44: 213$

8. Meziani F, Tesse A, David E, Martinez MC, Wangesteen R, Schneider $\mathrm{F}$, Andriantsitohaina R: Shed membrane particles from preeclamptic women generate vascular wall inflammation and blunt vascular contractility. Am J Pathol 2006, 169:1473-1483

9. Agouni A, Lagrue-Lak-Hal AH, Ducluzeau PH, Mostefai HA, DraunetBusson C, Leftheriotis G, Heymes C, Martinez MC, Andriantsitohaina $\mathrm{R}$ : Endothelial dysfunction caused by circulating microparticles from patients with metabolic syndrome. Am J Pathol 2008, 173:1210-1219

10. Mostefai HA, Meziani F, Mastronardi ML, Agouni A, Heymes C, Sargentini C, Asfar P, Martinez MC, Andriantsitohaina R: Circulating microparticles from patients with septic shock exert protective role in vascular function. Am J Respir Crit Care Med 2008, 178:1148-1155

11. Martinez MC, Tesse A, Zobairi F, Andriantsitohaina R: Shed membrane microparticles from circulating and vascular cells in regulating vascular function. Am J Physiol Heart Circ Physiol 2005, 288 : H1004-H1009

12. Geiser T, Buck F, Meyer BJ, Bassetti C, Haeberli A, Gugger M: In vivo platelet activation is increased during sleep in patients with obstructive sleep apnea syndrome. Respiration 2002, 69:229-234

13. Ayers L, Ferry B, Craig S, Nicoll D, Stradling JR, Kohler M: Circulating cell-derived microparticles in patients with minimally symptomatic obstructive sleep apnoea. Eur Respir J 2009, 33:574-580

14. Pelletier-Fleury N, Meslier N, Gagnadoux F, Person C, Rakotonanahary D, Ouksel H, Fleury B, Racineux JL: Economic arguments for the immediate management of moderate-to-severe obstructive sleep apnoea syndrome. Eur Respir J 2004, 23:53-60

15. Sleep-related breathing disorders in adults: recommendations for 
syndrome definition and measurement techniques in clinical research. The Report of an American Academy of Sleep Medicine Task Force. Sleep 1999, 22:667-689

16. Johns MW: A new method for measuring daytime sleepiness: the Epworth sleepiness scale. Sleep 1991, 14:540-545

17. Nieto FJ, Herrington DM, Redline S, Benjamin EJ, Robbins JA: Sleep apnea and markers of vascular endothelial function in a large community sample of older adults. Am J Respir Crit Care Med 2004, 169:354-360

18. Vandesompele J, De Preter K, Pattyn F, Poppe B, Van Roy N, De Paepe A, Speleman F: Accurate normalization of real-time quantitative RT-PCR data by geometric averaging of multiple internal control genes. Genome Biol 2002, 3:RESEARCH0034

19. Martin S, Tesse A, Hugel B, Martinez MC, Morel O, Freyssinet JM, Andriantsitohaina R: Shed membrane particles from $\mathrm{T}$ lymphocytes impair endothelial function and regulate endothelial protein expression. Circulation 2004, 109:1653-1659

20. Baguet JP, Hammer L, Levy P, Pierre H, Launois S, Mallion JM, Pepin $\mathrm{JL}$ : The severity of oxygen desaturation is predictive of carotid wall thickening and plaque occurrence. Chest 2005, 128:3407-3412

21. Yokoyama S, Korthuis RJ, Benoit JN: Hypoxia-reoxygenation impairs endothelium-dependent relaxation in isolated rat aorta. Am J Physiol 1996, 270:R1126-R1131

22. Amabile N, Heiss C, Real WM, Minasi P, McGlothlin D, Rame EJ, Grossman W, De Marco T, Yeghiazarians Y: Circulating endothelial microparticle levels predict hemodynamic severity of pulmonary hypertension. Am J Respir Crit Care Med 2008, 177:1268-1275

23. Bulut D, Maier K, Bulut-Streich N, Borgel J, Hanefeld C, Mugge A: Circulating endothelial microparticles correlate inversely with endothelial function in patients with ischemic left ventricular dysfunction. $\mathrm{J}$ Card Fail 2008, 14:336-340

24. Esposito K, Ciotola M, Schisano B, Gualdiero R, Sardelli L, Misso L, Giannetti G, Giugliano D: Endothelial microparticles correlate with endothelial dysfunction in obese women. J Clin Endocrinol Metab 2006, 91:3676-3679

25. Goichot B, Grunebaum L, Desprez D, Vinzio S, Meyer L, Schlienger JL, Lessard M, Simon C: Circulating procoagulant microparticles in obesity. Diabetes Metab 2006, 32:82-85
26. Aronsohn RS, Whitmore H, Van Cauter E, Tasali E: Impact of untreated obstructive sleep apnea on glucose control in type 2 diabetes. Am J Respir Crit Care Med 181:507-513

27. Schulz R, Mahmoudi S, Hattar K, Sibelius U, Olschewski H, Mayer K, Seeger W, Grimminger F: Enhanced release of superoxide from polymorphonuclear neutrophils in obstructive sleep apnea: impact of continuous positive airway pressure therapy. Am J Respir Crit Care Med 2000, 162:566-570

28. Dyugovskaya L, Lavie P, Lavie L: Phenotypic and functional characterization of blood gammadelta T cells in sleep apnea. Am J Respir Crit Care Med 2003, 168:242-249

29. Noda A, Nakata S, Koike Y, Miyata S, Kitaichi K, Nishizawa T, Nagata K, Yasuma F, Murohara T, Yokota M: Continuous positive airway pressure improves daytime baroreflex sensitivity and nitric oxide production in patients with moderate to severe obstructive sleep apnea syndrome. Hypertens Res 2007, 30:669-676

30. Lavie L: Oxidative stress-a unifying paradigm in obstructive sleep apnea and comorbidities. Prog Cardiovasc Dis 2009, 51:303-312

31. Christou K, Moulas AN, Pastaka C, Gourgoulianis KI: Antioxidant capacity in obstructive sleep apnea patients. Sleep Med 2003, 4:225-228

32. Barcelo A, Barbe F: [Oxidative stress and sleep apnea-hypopnea syndrome]. Arch Bronconeumol 2005, 41:393-399

33. Ohga E, Nagase $T$, Tomita T, Teramoto $S$, Matsuse $T$, Katayama $H$, Ouchi $Y$ : Increased levels of circulating ICAM-1. VCAM-1, and Lselectin in obstructive sleep apnea syndrome. J Appl Physiol 1999, $87: 10-14$

34. Ursavas A, Karadag M, Rodoplu E, Yilmaztepe A, Oral HB, Gozu RO: Circulating ICAM-1 and VCAM-1 levels in patients with obstructive sleep apnea syndrome. Respiration 2007, 74:525-532

35. Ryan S, McNicholas WT: Intermittent hypoxia and activation of inflammatory molecular pathways in OSAS. Arch Physiol Biochem 2008, 114:261-266

36. Nacher M, Serrano-Mollar A, Farre R, Panes J, Segui J, Montserrat JM: Recurrent obstructive apneas trigger early systemic inflammation in a rat model of sleep apnea. Respir Physiol Neurobiol 2007. 155:93-96 